\title{
BMJ Open Tensions in integrating clinician and educator role identities: a qualitative study with occupational therapists and physiotherapists
}

Sik Yin Ong, ${ }^{1}$ Mary Lee, ${ }^{1}$ Lee Sian Lee, ${ }^{2}$ Issac Lim, ${ }^{1}$ Kum Ying Tham ${ }^{3}$

To cite: Ong SY, Lee M, Lee LS, et al. Tensions in integrating clinician and educator role identities: a qualitative study with occupational therapists and physiotherapists. BMJ Open 2019;9:e024821. doi:10.1136/ bmjopen-2018-024821

- Prepublication history and additional material for this paper are available online. To view these files, please visit the journal online (http://dx.doi. org/10.1136/bmjopen-2018024821).

Received 22 June 2018

Revised 15 September 2018 Accepted 2 November 2018

Check for updates

(c) Author(s) (or their employer(s)) 2019. Re-use permitted under CC BY-NC. No commercial re-use. See rights and permissions. Published by BMJ.

${ }^{1}$ HOMER (Health Outcomes and Medical Education Research),

Group Education, National

Healthcare Group, Singapore,

Singapore

${ }^{2}$ Occupational Therapy, Institute of Mental Health, Singapore,

Singapore

${ }^{3}$ Emergency, Tan Tock Seng

Hospital, Singapore, Singapore

Correspondence to

Ms Sik Yin Ong;

sik_yin_ong@nhy.com.sg

\section{ABSTRACT}

Objective Clinician educators (CEs) frequently report tensions in their professional identities as clinicians and educators, although some perceive a reciprocal relationship between clinical and teaching roles. However, it is unknown if the shared meanings of clinicians' multiple job roles translate to identity verification. We sought to examine CEs' perceptions of their clinician and educator roles and the influence of their perceptions on the salience of their professional identities.

Design Qualitative individual interviews and focus groups, analysed using framework analytic approach.

Setting and participants 23 occupational therapy (OT) and 16 physiotherapy (PT) educators from two acute hospitals and one rehabilitation unit in Singapore. Results PT and OT CEs constructed shared meanings of their clinician and educator roles through overcoming feelings of unease and inadequacy, discovering commonalities and establishing relevance. However, shared meanings between clinician and educator roles might not necessarily lead to mutual verification of their professional identities. Individuals' cognitive flexibility and openness to additional roles, and organisations' expectations had a mediating effect on the identity integration process. Less experienced CEs reported feelings of distress juggling the competing demands of both clinician and educator roles, whereas more experienced CEs appeared to be more capable of prioritising their job roles in different situations, which could be a result of differences in adaptation to frequent interruptions in clinical setting. Emphasis on patient statistics could result in failure in achieving identity verification, leading to feelings of distress.

Conclusion Faculty developers should take into consideration the episodic nature of the educator identity construction process and develop induction programmes to assist CEs in building integrated identities.

\section{INTRODUCTION}

Clinician educators (CEs) play an important role in learners' socialisation and professional identity formation. Observing role models was perceived by new graduate therapists as crucial in building their confidence in decision making and helpful in learning
Strengths and limitations of this study

- A combination of individual interviews and focus groups was used to delve in-depth into the experiences of clinician educators, allow clinician educators to generate their own questions and discuss issues that are important to them.

- A simple drawing activity was incorporated into the focus groups/interviews to stimulate participants' reflexivity, and to encourage them to go beyond a verbal mode of thinking, thereby allowing a holistic narration of self.

- Despite efforts to achieve purposive sampling, our findings suggested that experienced clinician educators who were able to assume both clinician and educator roles with minimal tension were under-represented.

- Our study proposed that cognitive flexibility might have an impact on how clinician educators constructed shared meanings of their clinician and educator roles. Future studies may examine other characteristics of CEs such as their personalities and outlooks on life as these may influence the way they perceive the inter-relationship between their job roles.

- We only interviewed participants once, so we were unable to gain an understanding of dynamic changes in identity construction over time.

how to communicate and work as a therapist. $^{1}{ }^{2}$ However, CEs frequently reported challenges in fulfilling their teaching roles in clinical settings due to insufficient protected time, lack of hospital support and recognition, intrusion on work-life balance, and cultural perceptions about the legitimacy and credibility of the teaching role. ${ }^{3-5}$ They went through a transition in which their identity as a clinician was expanded to include a sense of being a CE. ${ }^{6}$ Competing demands and expectations from multiple job roles, ranging from balancing needs of patients and students to being a role model for both professional practice and for their learners, 
often led to tensions in their professional identities. ${ }^{6-10}$ Higgs and McAllister's phenomenological study ${ }^{6}$ with speech therapists found that successful clinical educators had to develop clinical competence, teaching skills and knowledge, and needed to develop a strong sense of (1) self, (2) relationship with others, (3) being a CE and (4) their agency as CEs.

Despite tensions experienced in integrating educator identity with primary clinician identity, studies revealed that individuals had the agency to resist negative messages concerning their teaching roles, adapt their practices and reconstruct their identities. ${ }^{11} 12$ Identity theory (IT) provides a useful theoretical framework for us to understand identity processes occurring within individuals in a situation. ${ }^{13}$ IT suggests identity processes are organised as a control system seeking to align input perceptions as closely to an identity standard as possible. An identity standard contains meanings defining who a person is, and is stored in memory. ${ }^{13}$ For example, a CE may define her educator identity as a sideline, whereas another $\mathrm{CE}$ may define his educator identity as one that has equal importance to his clinician identity. When one's identity standard is aligned with his/her perceptions in a situation, identity verification is achieved. When disturbances occur in the environment, an individual has the agency to change resources, control perceptions of self-relevant meanings in the situation, and/or alter behaviour such that one's perception in a situation is matched with his/ her identity standard. Successful identity verification leads to increased self-esteem, whereas failure in achieving identity verification results in negative emotional reactions. ${ }^{13}$

To better understand how to assist CEs in achieving identity verification, it is necessary for us to take a step back and examine how individuals create their identity standards. Meanings defining an identity standard influence one's behaviour and it is one's behaviour which in turn reinforces the meanings in one's identity standard. ${ }^{13}$ Meanings are integral to the identity construction process but little is known about how CEs construct meanings of their job roles. ${ }^{14}{ }^{15}$ Two recent studies looked at how physician-managers constructed meanings about their job roles and how these meanings influenced the integration of their identities.$^{15}$ Both studies revealed physician-managers who developed negative meanings of their managerial roles experienced difficulties in identifying with their managerial roles. ${ }^{15} 16$ Physician-managers who reconstructed meanings of their managerial roles to be aligned with their primary clinician identities, adapted their practices and integrated their newly acquired managerial identities with their primary clinician identities. ${ }^{16}$

Existing literature offers some understanding of how physician-managers construct meanings of their job roles, but these findings are not transferable to allied health CEs. For physician-managers, transiting from a clinician role into a clinician-managerial role may be a one-off phase in their career. For allied health CEs, they have to play both clinician and educator roles at work and transit frequently between these roles. ${ }^{17}$ Occupational therapy
(OT) and physiotherapy (PT) CEs may only assume educator roles for weeks or months depending on their students' or trainees' supervision period. This is unlike how clinicians develop their clinician identities where they go through training for an uninterrupted and extended period of time. Additionally, when there is competing attention from patients, CEs may drop all teaching duties to attend to patients. These unpredictable interruptions caused by turning the identity 'on' and 'off' may cause heightened distress. ${ }^{13}$ Lake and Bell's study ${ }^{18}$ showed that medical educators constructed common meanings between their educator and clinician roles and described a reciprocal relationship between both roles. However, it was unclear if the shared meanings between educator and clinician roles would facilitate identity verification. Our study thus sought to examine CEs' perceptions of their roles and identities so as to better understand the interaction of clinicians' perceptions and identity standards. We would propose strategies to help CEs construct their identity standards to achieve identity verification. Our research question was: How do OT and PT CEs perceive their clinician and educator role identities?

\section{METHODS}

\section{Context and setting}

This study was performed between October and December 2015 in two acute hospitals and one rehabilitation unit. The study sites were within a regional health system in Singapore. An education department was set up in 2010 to provide resources and support for medical, nursing and allied health educators. Educational leadership positions were given to identified CEs to assist in planning faculty development programmes. Educational retreats involving educational leaders in all institutions within the regional health system were conducted regularly to review the institution's educational directions.

The research team approached the heads of departments (HODs) in PT and OT, and explained the rationale and details of the research study. The HODs disseminated the study's information to their staff and provided the research team with details of the interested respondents. Written informed consent was obtained from participants. No financial incentive was given.

\section{Patient and public involvement}

Patients and the public were not involved in this study.

\section{Design}

We chose a qualitative approach as we sought to explore and gain an in-depth understanding of our participants' experiences and feelings in their own words. ${ }^{19}$ We adopted the constructivist paradigm in which knowledge is taken to be subjective and there are multiple, diverse interpretations of realities. ${ }^{20}$ We viewed identity as the meanings individuals attach reflexively to self, and is both created and co-created within social interactions. ${ }^{1421}$ 
Twenty-three OT and 16 PT CEs participated in 12 individual interviews or focus groups. The characteristics of the participants were listed in online supplementary appendix 1. Each interview/focus group was conducted by one or two of the research team members (SYO, ML, LSL). SYO was a trained researcher with some experience as CE. ML was an experienced qualitative researcher. LSL was a clinical educator lead and an experienced CE working in one of the acute hospitals in Singapore. Purposive sampling strategy was adopted to ensure educators with varying years of experience were represented in our study. We developed an interview template and revised the template based on feedback from a pilot interview with a researcher who had previous experience as an OT CE. This template was modified throughout the data collection process in order to capture and expand on emergent themes.

We chose a combination of focus groups and interviews because individual interviews allowed us to delve in-depth into individuals' experiences and perspectives, ${ }^{22}$ whereas focus groups gave us access to different forms of communication such as jokes and anecdotes that people used in day-to-day interaction, and encouraged participants to generate their own questions and discuss issues that were important to them. ${ }^{23}$ We made a conscious effort to ensure that LSL would not facilitate interviews that involved her colleagues. To protect their interests, participants were reminded not to disclose discussion content to third parties. During focus groups and interviews, participants were asked to use a word, image, phrase or metaphor to describe their roles as a clinician and an educator. We also provided participants the four identity alignment models (see online supplementary appendix 2) from O'Sullivan and Irby's study ${ }^{24}$ a modified version of Roccas and Brewer's ${ }^{25}$ models. Participants were then asked to draw an identity alignment model that best described their educator and clinician identities, and describe their models in as much detail as possible. We incorporated this simple visual task to stimulate participants' reflexivity and to encourage them to go beyond a verbal mode of thinking, thereby allowing a holistic narration of self. ${ }^{26}$ We kept memos during and after interviews/focus groups. Each focus group/interview took place in the respective hospitals, lasted between 50 and $100 \mathrm{~min}$ and were audio recorded. A research assistant was employed to transcribe the recordings. SYO checked all anonymised transcripts for accuracy.

\section{Analysis}

We analysed the transcripts using a framework analytic approach. ${ }^{27}$ This is a systematic approach involving sifting, sorting and charting data according to key issues and themes. The five key stages to a framework analytic approach are familiarisation, identifying a thematic framework, indexing, charting, and mapping and interpretation. We developed an initial index using emergent categories and themes derived from an initial open coding of one transcript and a priori theoretical considerations, which served as sensitising concepts in the analysis. SYO, $\mathrm{ML}$ and LSL analysed the transcripts individually using the index. We met to discuss our categories and themes after we analysed each transcript. Following that, we adjusted our index to include new categories and themes. We adhered to this process for all 12 transcripts. During our discussions, we brought our own interpretations of the findings based on our individual training backgrounds. We discussed differing perspectives to ensure that our underlying assumptions were exposed and challenged, and eventually reached consensus on the descriptive and analytic themes. This enhanced dependability of our results. We also kept an audit trail of all minutes of meetings, interview memos and coding structures. A copy of the Standards for Reporting Qualitative Research can be found in online supplementary appendix 3 .

\section{RESULTS}

We derived two main themes: perception of inter-relationship between job roles and identity integration. Figure 1 illustrated the relationship between identity integration and perception of inter-relationship between roles as a clinician and an educator. In this model, we identified three main strategies adopted by CEs to construct shared meanings of their clinician and educator roles and two dominant factors that promoted the perception of the reciprocal relationship between the clinical and teaching roles. The two arrows linking 'perception of inter-relationship between job roles' and 'identity integration' denoted that shared meanings of the job roles did not necessarily lead to integration of the clinician and educator identities. This process could be strengthened by individuals' cognitive flexibility and hindered by the presence of individual and structural tensions.

\section{Perception of inter-relationship between job roles}

Our data revealed most CEs recognised the significance of their educator roles and some described the educator role as part of the responsibilities of a clinician. They had a strong sense of responsibility and wanted to give their best to their learners. They emphasised clinical competence as one of the defining characteristics of the CE identity. When they first took up teaching roles, they questioned their own competence. They experienced misalignment between their identity standards and perceptions of their competence levels, resulting in negative thoughts and emotions. CEs were found to adopt various strategies to construct shared meanings between their clinician and educator roles.

\section{Adopted strategies}

Our OT and PT educators perceived the reciprocal relationship between clinician and educator roles in three main ways: overcoming feelings of unease and inadequacy, discovering commonalities, and establishing relevance. It appeared that CEs needed to overcome their feelings of unease and inadequacy before perceiving the 


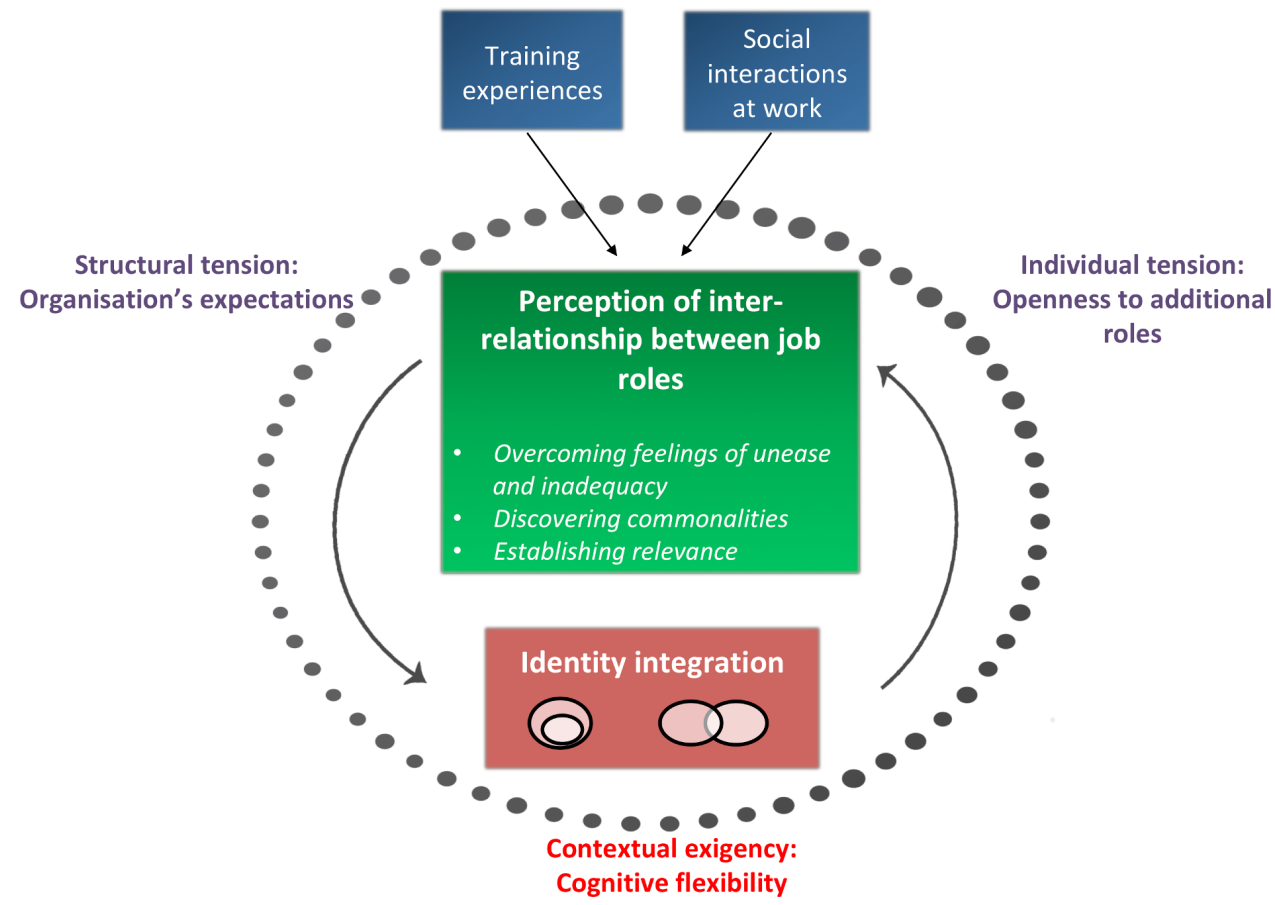

Figure 1 Model of identity integration and perception of inter-relationship between job roles.

inter-relationship between their new and existing job roles.

\section{Overcoming feelings of unease and inadequacy}

M3 (PT CE with 20 years' clinical and 18 years' teaching experience) and F26 (PT CE with 6years' clinical and 3 years' teaching experience) recounted their experiences and apprehensions when they were first 'thrown' into the educator role as a junior clinician. In the early career stage, CEs perceived themselves to be novices and insufficiently equipped as a CE. They stressed the importance of clinical competence as a prerequisite of being a CE, which could be interpreted as their identity standard. They eventually overcame their feelings of unease and inadequacy. This could be a result of a change in their identity standards over time or a conscious effort to change their perceptions and/or behaviours to align with their identity standards.

M3: In a very short time after starting work we all had to undertake some amount of student supervision. We felt we were still learning, how could we teach right? But after a while we realise that there is a big difference between a qualified person and student. Students still have a lot of apprehension, need to reflectively go through things before they can decide to act on it. (FG_3)

F26: I really worried a lot. I really wanted to make sure that I did a good job. I really wanted my student/ mentee to learn a lot. But subsequently when I'm taking the second and third batches of students, I start to look at it as a learning journey for me as well. (FG_9)

Novice CEs managing both roles also reported feelings of distress and experienced misalignment between their identity standards and perceived competence levels as CEs. They sometimes sought alternative rationales to justify their fit for the educator role.

F6 (OT): The image that comes to my mind when thinking about clinician and educator is that a toddler is trying to change a baby's diaper...I feel like I'm still learning, I still have a lot to digest but at the same time I'm trying to help and nurture this individual...I don't know whether I am ready for that yet but somehow you just do it. So I try to convince myself that even if you are not a good teacher, if you can at least impart that heart to the students, and the students can carry over and bring that heart in them to the patients, I am happy. (FG_3)

\section{Discovering commonalities}

It appeared that CEs developed shared meanings of their clinician and educator roles over time. Some perceived both roles to be performing similar functions, whereas others deemed skillsets were transferable from clinician role to educator role. They emphasised the commonalities between both roles instead of concentrating on their competence levels or deficits.

F9 (PT): Whatever the case, I am a clinician, but being an educator is always a part of it, whether it's to the family (or) the patient. You're always educating somebody... (as for) students, they're always just another part. You're just grooming the next generation. So I can't separate the two. (FG_3)

M9 (OT): I see my students as patients as well, it's just that they have different needs. So that helped me to get a good start with my first few students, and after 
that it just evolved to balancing patient care and facilitating my students' learning. (FG_7)

\section{Establishing relevance}

Other CEs rationalised training new therapists as a responsibility and a role of relevance and significance to being a therapist.

M1 (OT): By default, clinician is my primary goal and educator is a duty, (teaching) is a responsibility I need to give back to my profession. (FG_1)

F25 (PT): When you are teaching students, or when you are discussing with them about your patients and all that, it kind of helps the patient gets better, where the patient will benefit from the discussion and teaching as well. (FG_9)

\section{Factors that promote development of shared role-meanings}

We delineated how CEs adopted different strategies to construct shared meanings of their clinician and educator roles. The different strategies adopted by CEs demonstrated their agency in altering their perceptions and adapting practices. It was evident from our data that training experiences and social interactions at work played a substantial role in developing CEs' perceptions of the inter-relationships between both clinician and educator roles.

\section{Training experiences}

Educational training was useful in developing CEs' teaching competencies and creating opportunities for them to discern the relevance of educating work to their clinician role.

F11 (OT): We were initially trained to be clinicians. Why do we need to learn how to write and interpret standards and develop curriculum when we barely understand them? But after attending the courses, they really opened up my views about education. After we went for the course, we realised that "oh, we are the content expert, we are actually the best persons to develop all these courses, because this is bread and butter of what we do! So we know best what are the things to teach and how to teach it." (I_3)

\section{Social interactions at work}

Learners exerted strong influence on CEs' perceptions of their educator roles. CEs reported job satisfaction when they observed learners making improvements and practising professionally. On the contrary, some CEs expressed exasperation teaching passive learners and saw them as an interference to their clinical work.

F7 (OT): If I meet a good student, I really feel very happy, because we can talk about a lot of things, and they can carry out my teaching. (FG_3)

F21 (OT): If the student is willing to learn, I'm alright with using extra time to teach you but if you (student) are going to interfere with my patient care, then I'm sorry but patient care comes first. (FG_8)

In the busy healthcare context, CEs had to juggle heavy patient loads and dedicate time to train learners. Co-workers played an important role in CEs' work-life balance. It was helpful that there was no strong demarcation between clinician and educator roles and CEs were able to tap on peers for support in their clinical and teaching duties.

F2 (OT): You're not alone. You know that someone else is doing the same thing. (Be)cause you're a warrior... "Everybody must fight." (FG_2)

\section{Identity integration}

The second theme related to the integration of clinician and educator identities. We observed that the extent of integration of educator identity with the primary clinician identity was linked with salience of educator identity. A more salient identity is 'one that has a higher probability of being activated across different situations' ${ }^{28}$ CEs who described more salient educator identity also reported greater integration of their clinician and educator identities and less identity tension.

\section{Salience of educator identity}

Majority of CEs with less than 5 years of teaching experience described themselves primarily as clinicians, while more experienced CEs reported equally salient educator and clinician identities.

\section{Dominant clinician identity, secondary educator identity}

CEs might be cognisant of the inter-relationship between both job roles, but this did not necessarily lead to mutual verification of clinician and educator identities. Less experienced CEs were more likely to report a dominant clinician identity with a secondary educator identity despite knowing the relevance and importance of educator work.

F23 (OT): Teaching is a sideline. [Laughs] If you come, fine, the opportunity is there. I'm doing my clinical work, that's what you'll be doing eventually. Come, I can let you in but from the side.

Interviewer: Why is it not top right and top left or bottom left? Any reason?

F23: Because this (teaching) is more important. (FG_8)

The stickmen in the large clinician circle contrasted with the two female stickmen in the educator oval in figure 2. This highlighted the significant role a clinician plays in making a difference to a large population. Although the bi-directional arrows indicated her educator identity could expand and contract, the educator oval was placed on the bottom right of the clinician circle. This corroborated F23's verbatim of "Teaching is a sideline." Using drawing and verbal description, we could derive that F23 acknowledged educator as an important role, but she did not integrate the two identities. 


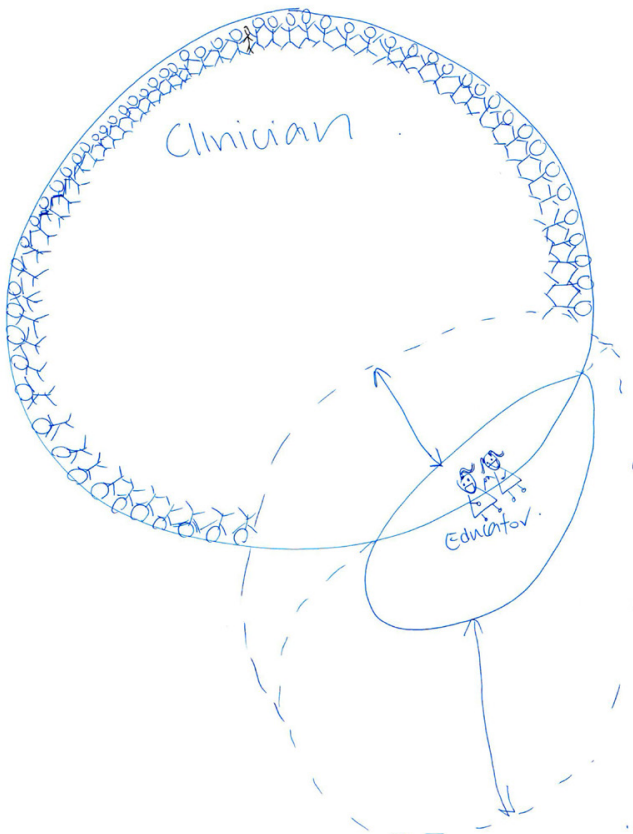

Figure 2 Identity model drawing of F23 (3 years' clinical experience, $2+$ years' teaching experience).

\section{Integrated clinician and educator identities}

It took time for CEs to integrate both clinician and educator identities. F16 (OT CE with 25 years' clinical and 23 years' teaching experience) described herself as an amoeba, capable of prioritising identity based on situational needs.

F16: So I see myself as a clinician first, the educator comes in when I have a student, then it becomes important, together with the students and the patient. Other than that, when I see my junior staff OTs, then I try to teach and do those things. And I've put them together because it's all part of me and me being the amoeba, I like to move around, slowly and where it goes, just moves. (FG_6)

F16 drew an amoeba to represent her professional identities (figure 3). The administrator identity was separated from the closely integrated clinician and educator identities. F16 went on to describe the dynamic and

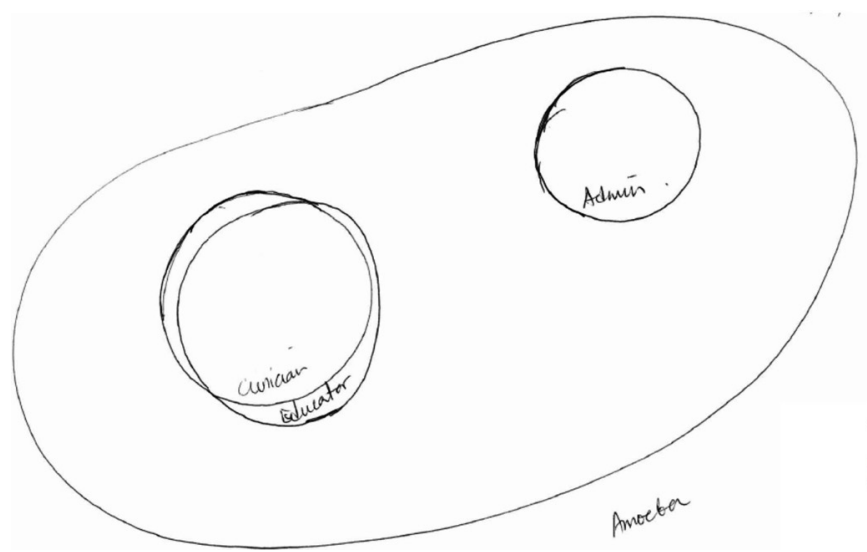

Figure 3 Identity model drawing of F16. situational nature of her professional identity using the metaphor 'amoeba', signifying that she was able to turn her educator identity 'on' and 'off' without distress.

F10 (PT CE with 16 years' clinical and 10 years' teaching experience) elaborated on how different roles took priority at different times of life and how she transited between her job roles without much tension.

F10: There are times when you need to be the daughter, you need to be the mum, you need to be the wife, and you need to dedicate time to be the employee. I think it's the same as the different roles that we have to juggle at work, it's just learning to be flexible. So it's the wheel of life that just keeps on going.

F10: If I receive a call, "F10, I have a pain case and I need you to guide me." "Oh, ok," then I'll drop everything. I'll go up to mentor the person, or walk through the case with the person. It's difficult to tell you what a typical work day is like. It's very variable! (I_2)

Although novice CEs were less likely to report an integrated identity, there was an exception. A relatively new CE with 3 years' clinical and 2years' teaching experience thought that it was easier for him to have one whole integrated identity. He described commonality between both roles where he positioned himself as a novice therapist learning and progressing to be a better CE.

M10 (OT): Yeah, mine is all integrated...I feel like being a clinician, I'm constantly learning; being an educator I'm also constantly learning. The whole thing is all about learning. Yeah, so even if I have a student then it's just like you're having someone along in your journey. I think that's for me. One identity is good enough. (FG_7)

Factors mediating the process of identity integration

From our analysis, we found that an individual's cognitive flexibility and openness to additional roles, and the organisation's expectations, mediated the process of inter-relating job roles and identity. In our setting, CEs had to transit between clinician and educator roles frequently and perform both roles concurrently. Those who were able to adapt quickly to changes appeared to be more likely to report integrated identities. Thus, cognitive flexibility was identified as a factor specific to our context under study, whereas organisations' expectations and individuals' openness to additional roles were general macro-level and micro-level factors applicable in other settings.

\section{Cognitive flexibility}

In our busy acute care setting, CEs faced high situational demands in which they had to manage patients' safety and learners' growth simultaneously. They had to ensure learners would not compromise patients' safety and also make calculated risks at times for learners' growth. Cognitive flexibility refers to the ability to efficiently and effectively alter one's behaviour according to the changes in an environment. ${ }^{29}$ 
We proposed that cognitive flexibility allowed CEs to switch between tasks and solve problems more smoothly and efficiently.

M1 (OT): I would observe from a distance so that I didn't undermine her authority. Because she did feedback to me that when I was around, she felt a bit nervous so I just stood away...We are in a gym format, it can be that I'm sitting on the other side, seeing another patient, at the same time I am also keeping a lookout for her as well. (FG_1)

Additionally, they had to manage emotional aspects of all parties.

F19 (PT): To the learners, it's very important that they get feedback so that they can improve. But to the patients, they feel very different, they will feel "oh, I'm a guinea pig." So, this is not just balancing the treatment...effectiveness and time, it's also striving a balance between this respect plus the... - [M9: Emotions.] - the emotional aspect of all parties. Also, we don't want to cause learner to feel not really able to participate in the learning journey at the end of it. $\left(\mathrm{FG}_{-}\right.$7)

Compared with experienced CEs, CEs with less than 5 years of teaching experience expressed feelings of distress as they juggled both roles with competing demands.

F4 (OT): I imagine myself in the cooking mama show [All laugh. F2 \& F3: Cooking Mama?] Because I need to meet a lot of timelines and lot of stresses then I also need to make sure the things are cooked. I imagine myself one hand holding a pan, one hand holding chopping board and the knife and everything. Because it's really very stressful and a lot of things to handle at one time...In the wards, you sometimes leave your mentee to try out cases so you let your mentee go and read the cases or even maybe, if they're more independent, to start the cases but then I still need to meet my own time and have my own cases to see right? So I also see my own cases and halfway I need to make sure my patient is settled then need to run back to my student and make sure she is safe (and) the patient. It's a lot of juggling with time and pressure and it's really under a cooking pot. Very hot also, in the kitchen. [All laugh] And also, the clock is running. (FG_2)

\section{Openness to additional roles}

Some CEs reported a stronger interest in clinical work than in educating work. This might influence the extent to which educator identity was integrated with primary clinician identity.

M7 (PT): I'm more interested in my clinical aspect now. When I take students, sometimes, it upsets me a bit when I cannot see my patients in the timeframe that I think I should. (FG_5)

\section{Organisations' expectations}

Majority of CEs reported there was considerable pressure in meeting patient statistics and coaching learners among other responsibilities.

F11 (OT): We go to school to learn to be clinician. When you come out to work, you realise, "Oh, you have to teach. Oh, you have to do all these administrative work. You never learn all these things in school. You have to handle complaints." [Laughs] (I_3)

F5 (OT): When the students need more assistance, the number of patients we give to them will definitely be lesser. Because we know that, if we are going to jam up, the patients are not going to be happy. So then, your satisfaction survey is going to be very badly affected. (I_1)

At the same time, an institutional culture emphasising learner-centredness might impact CEs' perceptions of the relationships with their learners. As described by M6 (PT CE with 7 years' clinical and 3 years' teaching experience), he perceived the need to change his character to suit learners' needs and found that to be challenging.

M6: Another challenge is we need to change our personality to fit into the student or the juniors. So it's an awareness of your own identity as well as your own personality to accommodate your mentee accordingly, so that you can match their personality. I suppose that comes into play...I'm sure, most of them (the educators) also have that ability to adjust according to the personalities of the mentees or students. (FG_4)

\section{DISCUSSION AND IMPLICATIONS \\ Contribution to literature}

Our study proposed a model to describe how OT and PT educators constructed shared meanings of their clinician and educator roles, and how these shared meanings were used to create integrated identities via mediating factors.

First, we illustrated how CEs constructed shared meanings of their clinician and educator roles through: (1) overcoming feelings of unease and inadequacy, (2) discovering commonalities and (3) establishing relevance. Many novice CEs perceived a lack in clinical competence for the educator role, and experienced misalignment between their identity standards and perceptions of their competence levels, leading to feelings of distress. Training experiences were vital to develop CEs' clinical and teaching competencies, increase their confidence in assuming the educator role, and reduce feelings of distress. For CEs who experienced identity non-verification, they might adopt alternative avenues to justify their fit for the educator role. One of the avenues was discovering the commonalities between the clinician and educator roles. CEs described educating as being inherent in their therapist role which involved educating patients and their family members on a daily basis. This finding contrasts with existing literature on medical educators' 
experiences in which medical educators perceived the similarities between clinical and educator roles predominantly as the transferability of communication skills and diagnostic thinking from clinical practice to educational situations. ${ }^{18}$ This is likely due to the difference in job nature between doctors and therapists - that is, patient education occupies a larger proportion of time in therapy work compared with medical work. Focusing on the commonalities between job roles and establishing the relevance and value of the educator role were strategies CEs adopted to integrate the educator identity with their primary clinician identity. This finding is consistent with Spyridonidis and colleagues' finding ${ }^{16}$ that physician-managers accorded high levels of salience to their new managerial identity when they aligned their medical practice with their managerial responsibilities. Browne and colleagues ${ }^{30}$ also found that senior medical educators adopted a wide range of strategies in adapting and transiting into their medical educator identity.

However, the aforementioned strategies are inadequate for changing meanings in the identity standard and for integrating professional identities. In our study, less experienced CEs reported feeling distressed when juggling both educator and clinician roles despite perceiving shared meanings between them. Experienced CEs appeared to have a greater ability to prioritise their job roles in different situations. This finding is also reported in other studies. ${ }^{61016}$ We propose that this difference is likely due to an individual's cognitive flexibility and openness to additional roles. Individuals with high cognitive flexibility are able to recognise and value diversity in viewpoints, cognisant of others' difficulties, reflect on them and choose appropriate behaviour depending on the situation. ${ }^{31}$ We infer that cognitive flexibility may be a construct that explains the difference in the extent of identity integration and degree of emotional distress between novice and experienced CEs. The difference between less and more experienced CEs can also be due to the episodic nature of the educator identity. ${ }^{13} \mathrm{PT}$ and OT CEs only take on educator roles for a designated period when they supervise learners. Experienced CEs undergo longer on-the-job training and adapt to the unpredictable interruptions occurring in the clinical setting, unlike novice CEs who have fewer opportunities to develop their educator identities. Existing research on interventions to develop cognitive flexibility is mainly limited to young children or individuals with anxiety and depression. ${ }^{31-33}$ We postulate that interventions that promote individuals' reflective perspectives are potentially useful as cognitive flexibility relates to the ability to identify elements of a situation, reflect on elements identified and take appropriate action. ${ }^{31}$

Besides individual-related factors, organisational-related factors also impacted the degree of identity integration of the professional identities. Faculty developers in O'Sullivan and Irby's study ${ }^{24}$ reported the emphasis on education in their institution had a positive impact on the development of their faculty developers' identities. Even though there were initiatives in place to support teaching in our study institutions, our participants reported that the concurrent emphasis on patient statistics was a source of disturbance that led to feelings of distress and subsequently hindered identity verification.

\section{Theoretical contribution}

IT suggests that if two identities share common meanings, it is easier to achieve mutual verification of the two identities because there are fewer different meanings to control. ${ }^{13}$ Our study showed that while common meanings in both identities facilitated the integration of an educator identity with a primary clinician identity, they did not necessarily lead to mutual verification of the professional identities. Individual factors such as cognitive flexibility and openness to additional roles, as well as institutional emphasis on patient statistics, had mediating effects on the process of identity integration. This finding can be verified and investigated in other settings to identify possible new theoretical constructs promoting mutual verification of professional identities at work.

\section{Implication for practice}

We advocate the provision of educational training in addition to on-the-job training to build CEs' teaching competence and self-confidence. Faculty developers should take into consideration the episodic nature of the educator identity construction process and develop induction programmes to assist novice CEs to build their educator identities. Role models and peer advocates should be engaged to highlight similarities in teaching and clinical roles and align the value of teaching to clinical work. These will assist CEs in constructing shared meanings of their clinician and educator roles. A collaborative culture within the department is vital to allow CEs to depend on their peers for support in times of conflicting demands from their multiple roles.

\section{Limitations}

We observe less experienced CEs feeling more distressed managing their professional roles compared with more experienced CEs. We postulate that this could be linked with CEs' cognitive flexibility and their perceptions of inter-relationship between the two roles. However, our study approach does not allow us to propose any factor or mechanism to account for this difference. Future studies may explore these differences and identify possible theoretical constructs to explain these differences.

\section{CONCLUSION}

Our research illustrated that CEs constructed shared meanings of their clinician and educator roles via overcoming feelings of unease and inadequacy, discovering commonalities, and establishing relevance. However, shared meanings of both roles were insufficient for identity verification. Perception of the inter-relationship between both roles and identity integration were mediated by individuals' cognitive flexibility and openness to 
assume educator role, and organisations' emphasis on patient statistics. Novice CEs experienced misalignment between perceptions of their competence levels and their identity standards as they perceived themselves to be not competent for the educator role. This resulted in failure to achieve identity verification, which in turn generated feelings of distress. Organisations should acknowledge that CEs do not have a smooth process in developing their educator identities due to episodic nature of the educator identity, and provide more support to CEs to facilitate identity verification.

Acknowledgements The authors wish to thank the institutions and individuals who participated in the research reported here.

Contributors SYO is a research analyst in HOMER (Health Outcomes and Medical Education Research), National Healthcare Group, Singapore. She was involved in study conceptualisation, study design, data collection and analysis, and led in writing the manuscript. ML is a principal research analyst in HOMER, National Healthcare Group, Singapore. She was involved in study design, data collection and analysis, and editing of the manuscript. LSL is a clinical educator lead and senior occupational therapist in the Institute of Mental Health, Singapore. She was involved in data collection and analysis, and editing of the manuscript. IL is the Head of HOMER, National Healthcare Group, Singapore. He was involved in study conceptualisation, study design and editing of the manuscript. KYT is an emergency senior consultant in Tan Tock Seng Hospital and Assistant Dean in Lee Kong Chian School of Medicine, Nanyang Technological University, Singapore. She was involved in study conceptualisation and editing of the manuscript.

Funding The authors have not declared a specific grant for this research from any funding agency in the public, commercial or not-for-profit sectors.

Competing interests None declared.

Patient consent for publication Not required.

Ethics approval Research ethics approval was obtained from the Institutional Review Board of the National Healthcare Group Domain Specific Review Board (NHG DSRB reference number: 2015/00483).

Provenance and peer review Not commissioned; externally peer reviewed.

Data sharing statement № additional data are available.

Open access This is an open access article distributed in accordance with the Creative Commons Attribution Non Commercial (CC BY-NC 4.0) license, which permits others to distribute, remix, adapt, build upon this work non-commercially, and license their derivative works on different terms, provided the original work is properly cited, appropriate credit is given, any changes made indicated, and the use is non-commercial. See: http://creativecommons.org/licenses/by-nc/4.0/.

\section{REFERENCES}

1. Robertson LJ, Griffiths S. Graduates' reflections on their preparation for practice. British Journal of Occupational Therapy 2009;72:125-32.

2. Morley M. Contextual factors that have an impact on the transitional experience of newly qualified occupational therapists. British Journal of Occupational Therapy 2009;72:507-14.

3. Kumar K, Roberts C, Thistlethwaite J. Entering and navigating academic medicine: academic clinician-educators' experiences. Med Educ 2011;45:497-503.

4. Collins JP, Smith MJ, Lambert T, et al. Sustaining the surgical educator workforce in Australia and New Zealand. ANZ J Surg 2011;81:411-7.

5. Bartle E, Thistlethwaite J. Becoming a medical educator: motivation, socialisation and navigation. BMC Med Educ 2014;14:110.

6. Higgs J, McAllister L. Being a clinical educator. Adv Health Sci Educ Theory Pract 2007;12:187-200.
7. Burton S, Boschmans SA, Hoelson C. Self-perceived professional identity of pharmacy educators in South Africa. Am J Pharm Educ 2013;77:210.

8. Sabel E, Archer J. Early Careers Working Group at the Academy of Medical Educators. "Medical education is the ugly duckling of the medical world" and other challenges to medical educators' identity construction: a qualitative study. Acad Med 2014;89:1474-80.

9. Rosenblum ND, Kluijtmans M, Ten Cate O. Professional identity formation and the clinician-scientist: A paradigm for a clinical career combining two distinct disciplines. Acad Med 2016;91:1612-7.

10. Sethi A, Ajjawi R, McAleer S, et al. Exploring the tensions of being and becoming a medical educator. BMC Med Educ 2017;17:62.

11. van Lankveld T, Schoonenboom J, Kusurkar RA, et al. Integrating the teaching role into one's identity: a qualitative study of beginning undergraduate medical teachers. Adv Health Sci Educ Theory Pract 2017;22:601-22.

12. Cantillon P, D'Eath M, De Grave W, et al. How do clinicians become teachers? A communities of practice perspective. Adv Health Sci Educ Theory Pract 2016;21:991-1008.

13. Burke PJ, Stets JE. Identity Theory. New York, NY: Oxford University Press, 2009.

14. Brown AD. Identities and Identity Work in Organizations. Int J Manag Rev 2015;17:20-40.

15. Cascón-Pereira R, Chillas S, Hallier J. Role-meanings as a critical factor in understanding doctor managers' identity work and different role identities. Soc Sci Med 2016;170:18-25.

16. Spyridonidis D, Hendy J, Barlow J. Understanding hybrid roles: The role of identity processes amongst physicians. Public Adm 2015;93:395-411.

17. Miller W. Developing a theory of clinical instructor identity using the experiences of medical laboratory science practitioners. Clin Lab Sci 2014;27:97-104.

18. Lake J, Bell J. Medical educators: the rich symbiosis between clinical and teaching roles. Clin Teach 2016;13:43-7.

19. Patton MQ. Qualitative Evaluation and Research Methods. California, USA: Sage Publications, 2002.

20. Bunniss S, Kelly DR. Research paradigms in medical education research. Med Educ 2010;44:358-66.

21. Monrouxe LV, Rees CE. Theoretical perspectives on identity: researching identities in healthcare education. In: Cleland J, Durning SJ, eds. Researching Medical Education, 2015:129-40.

22. Tavakol M, Sandars J. Quantitative and qualitative methods in medical education research: AMEE Guide No 90: Part II. Med Teach 2014;36:838-48.

23. Kitzinger J. Qualitative research. Introducing focus groups. BMJ 1995;311:299-302.

24. O'Sullivan PS, Irby DM. Identity formation of occasional faculty developers in medical education: a qualitative study. Acad Med 2014;89:1467-73.

25. Roccas S, Brewer MB. Social Identity Complexity. Pers Soc Psychol Rev 2002;6:88-106.

26. Bagnoli A. Beyond the standard interview: the use of graphic elicitation and arts-based methods. Qual Res 2009;9:547-70.

27. Ritchie J, Spencer L. Qualitative data analysis for applied policy research. In: Bryman A, Burgess R, eds. Analysing qualitative data. London, UK: Routledge, 1994:173-94.

28. Stryker S, Burke PJ. The past, present, and future of an identity theory. Soc Psychol Q 2000;63:284-97.

29. Dajani DR, Uddin LQ. Demystifying cognitive flexibility: Implications for clinical and developmental neuroscience. Trends Neurosci 2015;38:571-8.

30. Browne J, Webb K, Bullock A. Making the leap to medical education: a qualitative study of medical educators' experiences. Med Educ 2018;52:216-26.

31. Laureiro-Martínez D, Brusoni S. Cognitive flexibility and adaptive decision-making: Evidence from a laboratory study of expert decision makers. Strat Mgmt J 2018;39:1031-58.

32. Johnco C, Wuthrich VM, Rapee RM. The role of cognitive flexibility in cognitive restructuring skill acquisition among older adults. J Anxiety Disord 2013;27:576-84.

33. Deák GO. The Development of Cognitive Flexibility and Language Abilities. In: Advances in Child Development and Behavior, 2004:271-327. 